\title{
Surgical Treatment of Cardiac Anomalies in Malposi- tion of the Heart with Special Reference to Possibility for Total Correction
}

\author{
Togo Horivehi, EiJi Ishizawa, Yasuyuki Suzuki and \\ Yoshiyuki OKaDA \\ The Division of Thoracic and Cardiovascular Surgery, Tohoku \\ University School of Medicine, Sendai
}

\begin{abstract}
Horivom, T., Ishizawa, E., Suzuki, Y. and OKadA, Y. Surgical Treatment of Cardiac Anomalies in Malposition of the Heart with Special Reference to Possibility for Total Correction. Tohoku J. exp. Med., 1974, 113 (1), 1-15 Cardiac anomalies in 34 consecutive cases with malposition of the heart were classified according to Van Praagh and surgical treatment was reviewed with special reference to the possibility of total correction. Mirror image-dextrocardia and mesocardia are deemed mostly adaptable to total corrective surgery with the criteria of indication almost identical with VSD or tetralogy of Fallot. Dextrocardia and levocardia in heterotaxy, frequently too complex in malformation, are generally considered inaccessible for total corrective surgery at present. However, total correction may be applicable to some of these cases. ——— mesocardia; dextrocardia; levocardia; asplenia; total correction
\end{abstract}

Congenital cardiac anomalies associated with cardiac malposition have generally been considered difficult to diagnose and in many cases impossible to subject to total correction. From the point of view of functional normalization, however, total correction, even with complex configurations, would not necessarily be impossible if the anatomy could be adequately identified. The recent pathomorphological studies of Van Praagh (1968) facilitated a better understanding of complicated cardiac malformations. Development of cinecardioangiography has also contributed to relatively easier identification of anomalies both morphologically and topologically. This paper presents our experience during the past 13 years on 34 patients with cardiac malposition. All cases were grouped according to the classification of Van Praagh and were reviewed to their respective surgeries. Special reference is made to the possibility of total correction of various complex anomalies.

\section{Definitions and Terms}

Dextrocardia, levocardia and mesocardia may be defined as follows: Dextrocardia; the heart is intrathoracically right-sided with the apex oriented inferiorly to the right. Levocardia; the heart is normally left-sided with the apex oriented inferiorly to the left but has anomalous visceroatrial situs. Mesocardia; the heart locates in the middle of the chest with the apex oriented anteroinferiorly or equivocally right- or leftward.

Received for publication, February 12, 1974. 

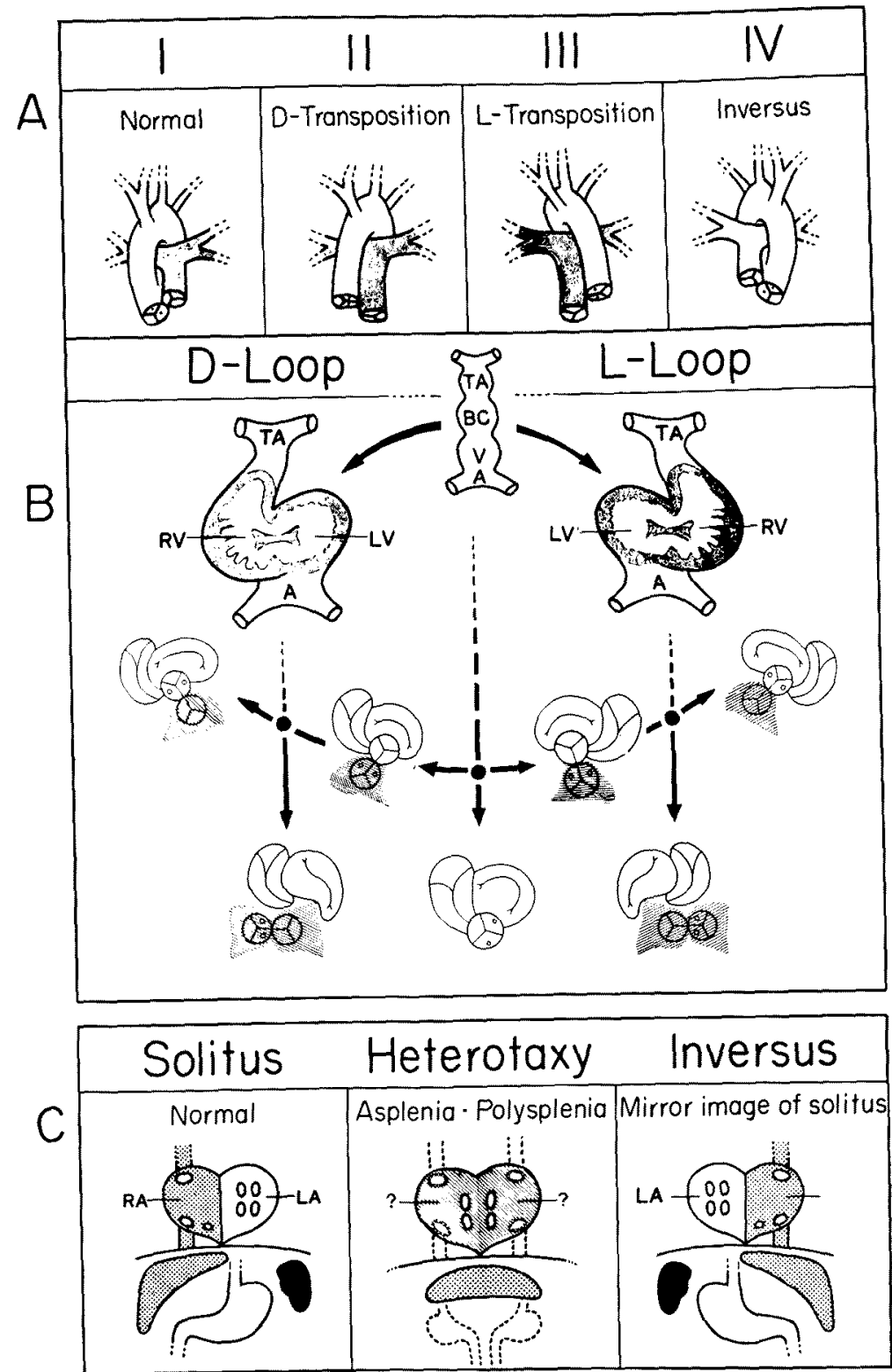

Fig. 1. Localization and type of the ventricle, great arteries and viscera, 3 basic patterns (A, B and C) (rearranged combination from Van Praagh's figurations (1968)).

Top: Pattern A "Relation of the great arteries." There are 4 patterns, I, II, III and IV. Note the height of level of the semilunar valves; Inversus is a mirror image of Normal.

Middle: Pattern B "Ventricular loop and conotruncus"; in the top, a torsion of the bulbus cordis (BC) rightward turns out D-loop and leftward L-loop; in the middle, horizontal view of the semilunar valves, atrioventricular valves and conus (shaded area) rotation of $\mathrm{BC} 30^{\circ}$ to the right to D-transposition, further $150^{\circ}$ to the 
Since this classification, though visually clear, is not based on developmental or pathomorphological considerations, an essential understanding of the associated anomalies may be obscured.

In the present paper, detailed classification is made, according to Van Praagh, by analysis of three principal cardiac segments; the great arteries, the ventricular loop and the visceroatrial situs (Fig. 1A, B and C). There are 4 patterns $(I \sim I V)$ in the relationship of the great arteries (Fig. IA). The two basic ventricular loops with conotruncus (Fig. IB) can further be divided into 4 subpatterns. Furthermore 3 intermediate patterns exist between those subpatterns. The visceroatrial situs (Fig. 1C), independent of the above 2, consists of situs solitus, situs inversus and heterotaxy. Heterotaxy only includes asplenia and polysplenia in this classification.

\section{Materials and Results}

Between 1960 and 1973, 34 instances of cardiac malpositions were found in 1,600 cases of congenital heart disease seen at the Department of Surgery, Tohoku University Hospital, Sendai. There were 18 males and 16 females. The average age was 5.5 years, ranging from 10 days to 20 years. There were 12 cases of mesocardia, 17 of dextrocardia and 5 of levocardia.

\section{Mesocardia}

In 12 patients, ages ranging between 4 months and 16 years, predominant was the III. L-loop. Solitus, so called "corrected transposition of the great arteries, Cardell B-3," seen in 9 cases. The other 3 patients shared I.D-loop. Solitus in 2 and IV.L-loop.Inversus in 1. The III.L-loop.Solitus was most frequently associated with pulmonary stenosis (PS) and ventricular septal defect (VSD), resulting similar hemodynamic stage to PS, VSD, or tetralogy of Fallot in many cases. Other anomalies seen in mesocardia were L-loop double outlet right ventricle with the arteries originating from the anatomical right (left-sided) ventricle, coarctation, mitral atresia in L-loop. Nine of these 12 patients were operated upon. One case with mitral atresia in L-loop was improved by superior vena cava and right pulmonary artery shunt operation (C-PA shunt), and in 8 cases corrective surgery including 3 reconstructions of pulmonary trunks were performed. Of these, one (Case M-1 in Table 1) died from oversight of coarctation, and the other (Case M-7) treated with a "valve-bearing tube-graft made of autologous pericardium" (Horiuchi et al. 1971) for reconstruction of pulmonary trunk died 36 hours postoperatively from low

Fig. 1.

right to Normal, $55^{\circ}$ to the left to L-transposition, and further $150^{\circ}$ to the left to Inversus; in the bottom, center shows anatomical situations seen in atretic conus (Paul et al. 1970) of truncus arteriosus, rotation of $\mathrm{BC} 90^{\circ}$ to the right or left to bilateral conus seen in double outlet right ventricle. D-loop and L-loop are expressed as pattern $\mathrm{II}^{\prime}$ and pattern $\mathrm{III}^{\prime}$ respectively in these situations.

Bottom: Pattern C "Visceroatrial situs," Inversus is mirror image of Solitus; in Asplenia-polysplenia syndrome, situs can not be determined and called as Heterotaxy.

TA, truncus arteriosus; BC, bulbus cordis; V, ventricle of bulboventricular loop; A, atrium.

For example, "I.D-loop. Solitus" is normal heart and "IV.L-loop. Inversus" is inverted heart, a mirror image of normal. 
TABLE 1 .

\begin{tabular}{lllll}
\hline Case & Age & Group & Cyanosis & Major anomaly \\
\hline M-1 & 4 months & III.L-loop.Sol. & - & VSD, Coarc. \\
M-2 & 9 months & I.D-loop.Sol. & - & VSD \\
M-3 & 1 year & III.L-loop.Sol. & - & VSD \\
M-4 & 1 year & III.L-loop.Sol. & Mitral atresia \\
M-5 & 4 years & IV.L-loop.Inv. & - & VSD+PH \\
M-6 & 4 years & I.D-loop.Sol. & + & ECD +PH \\
& & & & \\
M-7 & 4 years & III'.L-loop.Sol. & + & DORV \\
M-8 & 5 years & III.L-loop.Sol. & + & TF \\
M-9 & 10 years & III'.L-loop.Sol. & + & DORV \\
M-10 & 11 years & III.L-loop.Sol. & - & PS? \\
M-11 & 13 years & III.L-loop.Sol. & + & PS \\
M-12 & 16 years & III.L-loop.Sol. & + & TF \\
\hline
\end{tabular}

Abbreviations in Tables 1, 2 and 3.

absent IVC, absence of inferior vena cava with azygos continuation; A-PA, Waterson's shunt operation; ASD, atrial septal defect; bilat. SVC, bilateral superior vena cava; B-PA, Blalock's shunt operation; Coarc., coarctation of aorta; cor. TGA, corrected transposition of great arteries; C-PA, Glenn's cavo-pulmonary arterial shunt operation; DORV, double outlet right ventricle; ECD, endocardial cushion defect; Het., Heterotaxy; Inv., inversus;
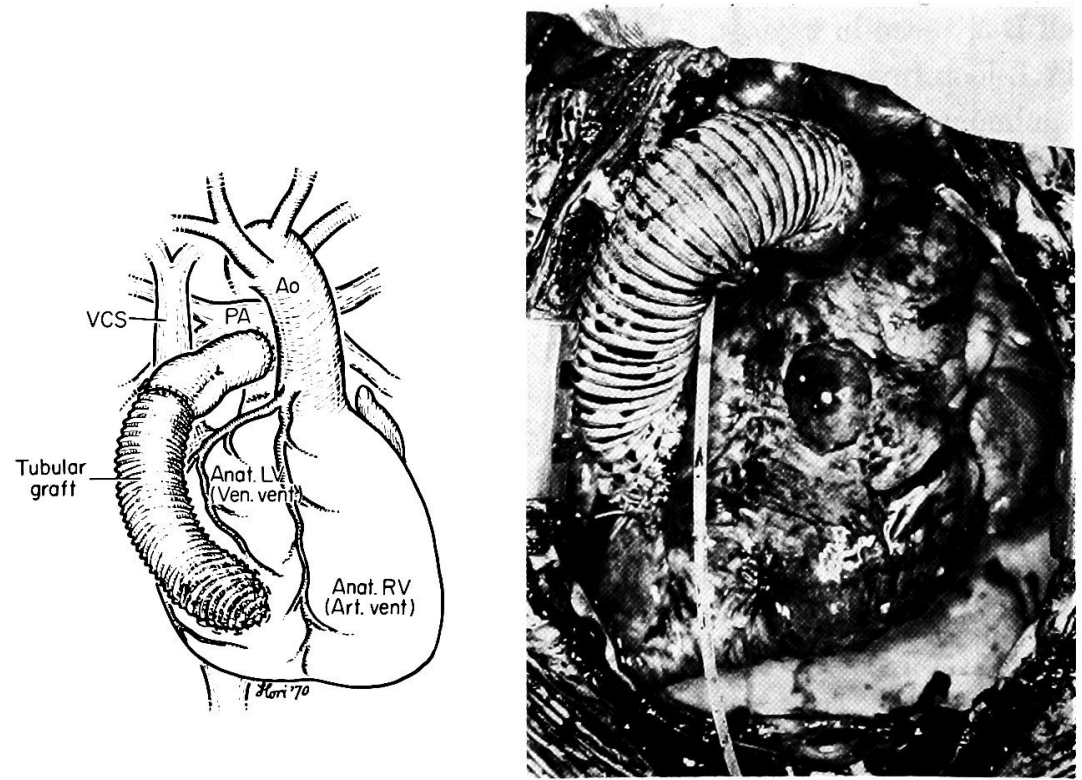

Fig. 2. Case M-8. Diagram and operative photograph.

cardiac output syndrome.

Case M-8: A 5-year-old boy, diagnosis: III.L-loop. Solitus, with Fallot-type corrected transposition of the great arteries and bilateral superior venae cavae.

Cardiac murmur was noticed soon after birth. While physical development 
Mesocardia

\begin{tabular}{|c|c|c|c|}
\hline Minor anomalies & Palliation & Total correction & Note \\
\hline TI, cor. TGA & & $\begin{array}{l}\text { Yes (died) } \\
\text { Yes (alive) }\end{array}$ & $\begin{array}{l}\text { Oversight of Coarc. } \\
\text { Cured }\end{array}$ \\
\hline cor. TGA & & Not yet & Not yet operated \\
\hline VSD, PDA, cor. TGA & $\begin{array}{l}\text { C-PA } \\
\text { (alive) }\end{array}$ & & Improved \\
\hline Mitral cleft & & Yes (alive) & Cured \\
\hline $\begin{array}{l}\text { Mitral \& tricuspid cleft, } \\
\text { bilat. SVC, absent IVC }\end{array}$ & & Yes (alive) & $\begin{array}{l}\text { Improved, residual shunt } \\
\text { and persistent } \mathrm{PH}\end{array}$ \\
\hline PS, cor. TGA & & Yes (died) & $\begin{array}{l}\text { Pneumothorax, low } \\
\text { output sydrome }\end{array}$ \\
\hline bilat. SVC, cor. TGA & & Yes (alive) & Cured \\
\hline PS & & Yes (alive) & Cured \\
\hline cor. TGA & & No & Exploratory thoracotomy \\
\hline cor. TGA & & Yes (alive) & Cured \\
\hline cor. TGA & & Yes (alive) & Cured \\
\hline
\end{tabular}

PA, pulmonary atresia; PAPVR, partial anomalous pulmonary venous return; PDA, patent ductus arteriosus; PH, severe pulmonary hypertension; PS, pulmonary stenosis; $\mathrm{SA}$, single atrium; Sol., solitus; SV, single ventricle; TAPVR, total anomalous pulmonary venous return; TF, tetralogy of Fallot; TI, tricuspid insufficiency; VSD, ventricular septal defect.

was considered normal, he developed cyanosis at the age of 2 years. Parents were consanguineous, the father had paroxysmal tachycardia and mother was found to have visceroatrial situs inversus. At the time of admission on January 6,1970 , his red blood cell count was $603 \times 10^{4}$ per $\mathrm{mm}^{3}$, the hemoglobin $16.8 \mathrm{~g} / 100$ $\mathrm{ml}$ and the hematocrit $53 \%$. A harsh systolic murmur, grade $3 / 6$, was audible along the left sternal border. Electrocardiogram showed RS patterns in the right precordial leads except for a $q R$ pattern in $V_{6 R}$, and negative $P$ waves in the limb leads and aVF suggesting left atrial rhythm. Cardiac catheterization showed identical pressures in both ventricles, with a right to left shunt ratio of $26 \%$ and a left to right shunt ratio of $36 \%$ at the ventricular level. Selective cineangiocardiography established the diagnosis. Total corrective operation was performed under extracorporeal circulation on February 3, 1970. An oblique ventriculotomy towards the apex was made on the right-sided ventricle, and the anterior papillary muscle of the mitral valve was retracted downward. A VSD of $14 \mathrm{~mm}$ in diameter located just below the pulmonary valve was closed with a Teflon patch. An attempt to relieve the pulmonary stenosis proved unsuccessful because of the highly narrowed pulmonary valve-ring. A valve-bearing tubular graft was then constructed from pericardium (size $70 \times 55 \mathrm{~mm}$ ) and a woven Teflon vascular prosthesis $20 \mathrm{~mm}$ in diameter (Horiuchi et al. 1971). This graft was interposed between the ventriculotomy in the venous ventricle and the bifurcation of the pulmonary artery (Fig. 2). After termination of extracorporeal circulation, the systolic pressures at the right ventricle and the pulmonary artery were $45 \mathrm{~mm} \mathrm{Hg}$ with a systemic pressure of $70 \mathrm{~mm} \mathrm{Hg}$, showing satisfactory hemodynamics. Mild congestive heart failure immediately after surgery little affected a generally favorable 

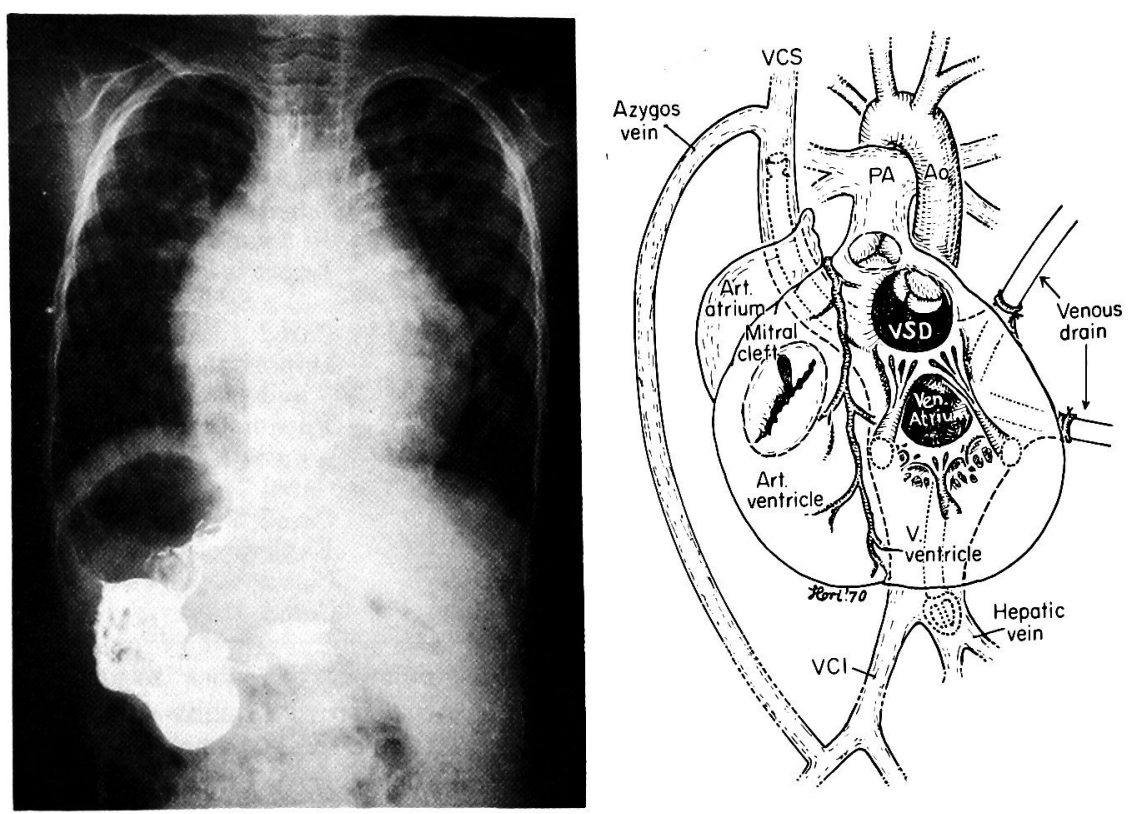

Fig. 3. Case M-5. Preoperative roentgenogram and diagram.

postoperative course. Cardiac catheterization 1.5 months after surgery revealed a right ventricular pressure of $75 / 16 \mathrm{~mm} \mathrm{Hg}$ and a pulmonary artery (graft) pressure of $53 / 15 \mathrm{~mm} \mathrm{Hg}$. It was also demonstrated that the new conduit was the main channel to the lung without evident pulmonary insufficiency. Now 3 years after surgery, the boy is doing well and is active in primary school.

Case M-6 had an endocardial cushion defect associated with severe pulmonary hypertension. Persistence of pulmonary hypertension complicated postoperative management, but finally it was brought under control. Another case, described below, had a morphologically special feature in the mesocardia group.

Case M-5: A 4-year-old girl, diagnosis: IV.L-loop.Inversus, VSD associated with severe pulmonary hypertension and mitral insufficiency.

Heart disease was initially detected at 3 months of age. She had frequent upper respiratory infections and failed to thrive. Tachypnea and mild cyanosis on exertion were noted after 6 months of age. At the time of admission on November 22, 1967, a harsh systolic murmur (grade 4/6) was heard at the fourth intercostal space along the left sternal border with an accentuated pulmonary second sound and a palpable thrill over the precordium. An electrocardiogram showed evidence of ventricular hypertrophy and right axis deviation $\left(+170^{\circ}\right)$. Cardiac catheterization demonstrated a systolic pulmonary-systemic pressure ratio as high as 0.84 , with a left to right shunt ratio of $70 \%$ and a right to left of $12 \%$ at the ventricular level. Selective cineangiocardiography confirmed anatomically inverted ventricles and great arteries. On December 19, 1967, the patient underwent total intracardiac repair under extracorporeal circulation. The anterior 
descending coronary artery was separating the two ventricles, the left-sided venous atrium (anatomically right atrium) lying at the back of the heart (Fig. 3). Partial cardiopulmonary bypass was instituted using an aortic cannula and an inferior vena cava cannula for core cooling. At a pharyngeal temperature of $27^{\circ} \mathrm{C}$, another cannula was inserted into the right superior vena cava through the coronary sinus in the left-sided atrium and total bypass was instituted. A transverse incision of the venous (left-sided) ventricle at the anterior region disclosed a septal defect just below the pulmonary valve. This was closed with folded pericardium. Then, the arterial (right-sided) atrium was opened longitudinally and a mitral cleft at the anterior leaflet was oversewn to reduce valvular insufficiency. After cessation of extracorporeal circulation, pressures in the venous ventricle and pulmonary artery became normal. She is in fairly good condition 2 years after operation.

\section{Dextrocardia}

Seventeen patients with dextrocardia, ages ranging from 10 months to 19 years, were divided into 2 groups; i.e., IV.L-loop.Inversus (mirror image-dextrocardia) and Heterotaxy. Except for one case with complete transposition of the great arteries, all others with mirror image-dextrocardia had relatively simple anomalies, mainly VSD or tetralogy of Fallot. Cases D-4 and D-5 (Table 2) had only a VSD but had not been offered surgical correction only because of having dextrocardia, and were found to have already developed Eisenmenger's syndrome at the time of admission. Two of 3 cases with tetralogy of Fallot, were subjected to total correction, one of which died from postoperative complications. One (Case D-1) is scheduled for total correction. A case of dextrocardia with transposition of the great arteries, a relatively rare anomaly, is described below.

Case D-3: A 5-year-old girl with a diagnosis of III.L-loop.Inversus and complete transposition of the great arteries associated with VSD and PS.

Soon after birth, she was found to have cyanotic disease and dextrocardia. At the age 3, a diagnosis of complete transposition of the great arteries with VSD and PS was made by cardiac catheterization. Three months later, she suffered from epileptic attacks and right hemiplegia following persistent mild fever. A cerebral abscess in the left cranial motor area was diagnosed and she underwent a craniotomy with success, though right hemiplegia remained. One year later, in November 1972, she was admitted for total correction of her cardiac defect. She had severe cyanosis and polycythemia (RBC $926 \times 10^{4}$ per $\mathrm{mm}^{3}, \mathrm{Hb} 21.4 \mathrm{~g} / 100$ $\mathrm{ml}$, Hct $75 \%$ ). No Howell-Jolly or Heinz bodies were detected in red blood cells. Angiocardiography and gastrointestinal radioscopy suggested inverted situs. The pressure gradient between the anatomical left ventricle and the pulmonary artery was $78 \mathrm{~mm} \mathrm{Hg}$. On December 11, 1972, she was subjected to total correction with the intra-atrial pericardial baffle technique under deep hypothermia by means of combined surface and core cooling. The patient was surface cooled to the pharyngeal temperature $30^{\circ} \mathrm{C}$ and a median sternotomy was made, and a piece of pericardium $70 \times 55 \mathrm{~mm}$ was excised. The aorta was situated leftward and anterior 
Table 2.

\begin{tabular}{|c|c|c|c|c|}
\hline Case & Age & Group & Cyanosis & Major anomaly \\
\hline D-1 & 5 months & IV.L-loop.Inv. & H & $\mathrm{TF}$ \\
\hline D-2 & 1 year & III-IV.L-loop.Inv. & H & Pseudotruncus \\
\hline D-3 & 5 years & III.L-loop.Inv. & H & Complete TGA \\
\hline D-4 & 8 years & IV.L-loop.Inv. & + & $\mathrm{VSD}+\mathrm{PH}$ \\
\hline D-5 & 10 years & IV.L-loop.Inv. & + & $\mathrm{VSD}+\mathrm{PH}$ \\
\hline D-6 & 11 years & IV.L-loop.Inv. & H & TF \\
\hline D-7 & 19 years & IV.L-loop.Inv. & H & $\mathrm{TF}$ \\
\hline D-8 & 10 days & III.L-loop.Het. & W & Cor biloculare \\
\hline D-9 & 1 month & II.D-loop.Het. & \# & Cor biloculare \\
\hline D-10 & 5 months & III-IV.L-loop.Het. & H & Pseudotruncus \\
\hline D-11 & 10 months & III'.L-loop.Het. & W & DORV \\
\hline D-12 & 1 year & III.L-loop.Het. & H & Cor biloculare \\
\hline D-13 & 1 year & IV.L-loop.Het. & H & Cor biloculare \\
\hline D-14 & 2 years & III-IV.L-loop.Het. & H & Pseudotruncus \\
\hline D-15 & 3 years & III.L-loop.Het. & W & SV \\
\hline D-16 & 8 years & IV.L-loop.Het. & - & PAPVR \\
\hline D-17 & 17 years & II'.D-loop.Het & m & DORV, A-V canal \\
\hline
\end{tabular}
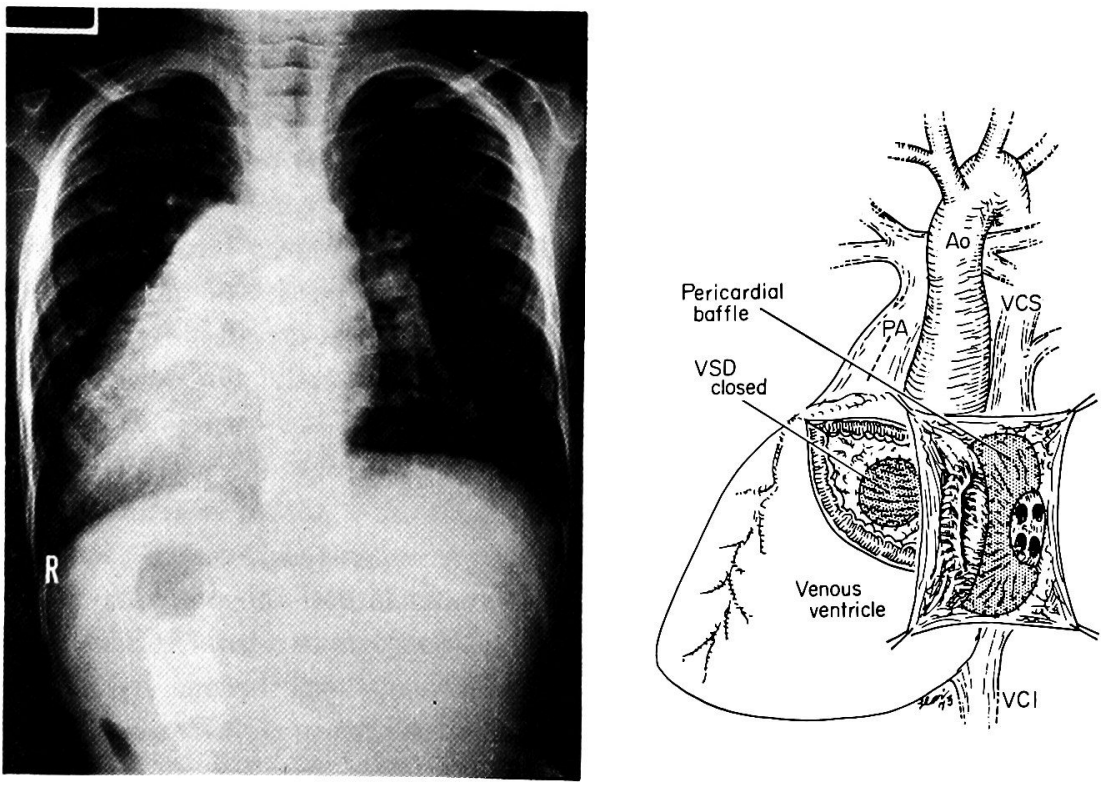

Fig. 4. Case D-3 Preoperative roentgenogram and diagram. 
Dextrocardia

\begin{tabular}{|c|c|c|c|}
\hline Minor anomalies & Palliation & Total correction & Note \\
\hline \multirow{6}{*}{$\begin{array}{l}\text { PDA } \\
\text { VSD,PS } \\
\text { absent IVC }\end{array}$} & \multirow[t]{6}{*}{ B-PA(died) } & Not yet & Not yet operated \\
\hline & & Yes (alive) & Cured \\
\hline & & No & $\begin{array}{l}\text { Not operated because of } \\
\text { Eisenmenger's complex }\end{array}$ \\
\hline & & No & $\begin{array}{l}\text { Not operated because of } \\
\text { Eisenmenger's complex }\end{array}$ \\
\hline & & Yes (alive) & Cured \\
\hline & & Yes (alive) & $\begin{array}{l}\text { Died from cerebral embo- } \\
\text { ly } 9 \text { days after operation }\end{array}$ \\
\hline $\begin{array}{l}\text { PS, PDA, bilat. SVC, } \\
\text { absent IVC }\end{array}$ & B-PA(died) & & \\
\hline $\begin{array}{l}\text { PA, PDA, A-V canal, } \\
\text { TAPVR, absent IVC }\end{array}$ & A-PA(died) & & \\
\hline PDA, bilat. SVC & A-PA(alive) & & Improved \\
\hline $\begin{array}{l}\text { ASD, PS, PAPVR, } \\
\text { bilat. SVC }\end{array}$ & A-PA(died) & & \\
\hline $\begin{array}{l}\text { PS, A-V canal, bilat. } \\
\text { SVC }\end{array}$ & B-PA(alive) & & Improved \\
\hline $\begin{array}{l}\text { PA, PDA, A-V canal, } \\
\text { bilat. SVC }\end{array}$ & B-PA(alive) & & Improved \\
\hline $\begin{array}{l}\text { SA, A-V canal, } \\
\text { PDA }\end{array}$ & & & Died before operation \\
\hline $\begin{array}{l}\text { PS, PAPVR A-V } \\
\text { canal? }\end{array}$ & B-PA (alive) & & Improved \\
\hline ASD, absent IVC & & Yes (alive) & $\begin{array}{l}\text { Cured } \\
\text { [Polysplenia] }\end{array}$ \\
\hline ASD, PS & B-PA(alive) & & Improved \\
\hline
\end{tabular}
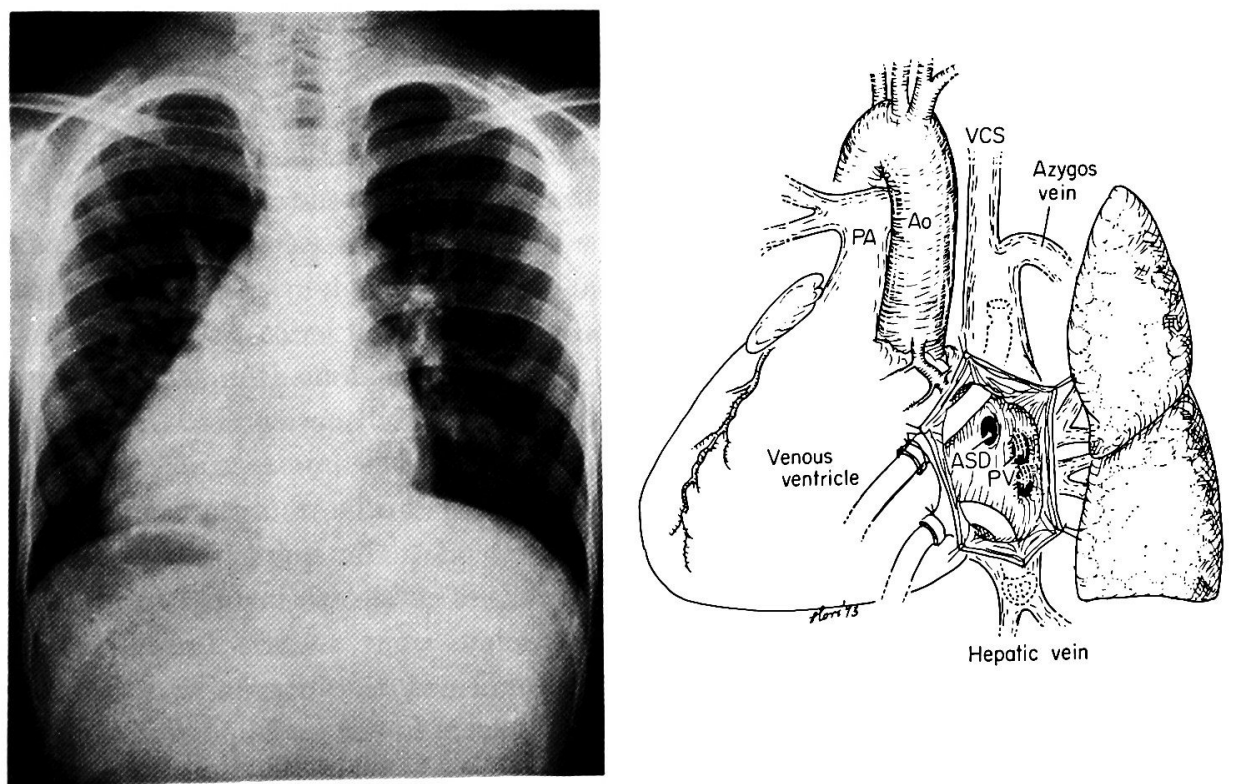

Fig. 5. Case D-16. Preoperative roentgenogram and diagram. 
TABLE 3.

\begin{tabular}{ccccc}
\hline Case & Age & Group & Cyanosis & Major anomaly \\
\hline L-1 & 2 months & I.D.loop.Het. & - & VSD \\
L-2 & 6 months & II.D-loop.Het. & H & SV \\
L-3 & 2 years & II.D-loop.Het. & W & SV \\
L-4 & 4 years & II.D-loop.Het. & $H$ & A-V canal+PS \\
L-5 & 20 years & II.D-loop.Het. & H & SV? \\
\hline
\end{tabular}

to the pulmonary artery, and the superior and inferior venae cavae and the venous atrium were on the left side, showing a position identical with a mirror image of complete transposition of the great arteries. Utilizing a heart-lung machine for core cooling, the pharyngeal temperature was further lowered from $26^{\circ} \mathrm{C}$ to $17.4^{\circ} \mathrm{C}$. In the mean time, the valvular PS was removed and the VSD was closed with Teflon patch through a ventriculotomy at the anatomical right ventricular outflow tract. Then, under complete circulatory arrest at $18^{\circ} \mathrm{C}$ for 22 minutes, the pericardial piece was sewn up around the pulmonary venous orifices. The rest of the intra-atrial baffle procedure was completed while the body was rewarmed with the aid of extracorporeal circulation. Atrioventricular dissociation persisted with a rate of $75 / \mathrm{min}$ one month after surgery. However, the recovery was uneventful.

Heterotaxy-dextrocardia encountered in 10 cases was more complex than simple mirror image-dextrocardia, including multiple anomalies, such as cor biloculare, pseudotruncus, double outlet right ventricle, A-V canal, and anomalous pulmonary venous return. Cyanosis was prominent in many cases. Total correction was considered impossible in all but one. Shunt operations were performed by Blalock-Taussig procedure (B-PA) in 5 cases and by Waterson's technique (A$\mathrm{PA}$ ) in 3 , and the results were considered successful in 5 cases. Cyanosis at rest was abolished postoperatively with remarkable improvement in physical activity.

Case D-16 was the only case totally corrected in this series. An 8-year-old girl was diagnosed as IV.L-loop.Heterotaxy, partial anomalous pulmonary venous return associated with an atrial septal defect, and absent inferior vena cava with azygos continuation.

This asymptomatic girl was first noted to have a cardiac murmur at the preschool check-up. A chest roentgenogram showed markedly increased pulmonary vascularity and the stomach bubble on the right. The electrocardiogram demonstrated RSr patterns in $V_{2}$ and $V_{3}$ and incomplete right bundle branch block. Cardiac catheterization and cineangiography confirmed the diagnosis. The leftto-right shunt ratio was $60 \%$ at the atrial level. Later an angiogram of the abdominal arteries convincingly suggested polysplenia. On February 3, 1967, left thoracotomy revealed a bilobed left lung. The left pulmonary veins drained 
Levocardia

\begin{tabular}{llll}
\multicolumn{1}{c}{ Minor anomalies } & Palliation & Total correction & Note \\
\hline $\begin{array}{l}\text { PDA, PAPVR, absent } \\
\text { IVC }\end{array}$ & $\begin{array}{c}\text { PA-banding } \\
\text { (died) }\end{array}$ & $\begin{array}{c}\text { Misdiagnosis } \\
\text { ASolysplenia] } \\
\text { ASD, PDAPA, TAPVR, }\end{array}$ & B-PA (died) \\
$\begin{array}{l}\text { A-V canal, bilat. SVC } \\
\text { ASD, PDA, PA, bilat. }\end{array}$ & A-PA (alive) & Improved \\
$\begin{array}{l}\text { SVC, absent IVC } \\
\text { SA, bilat. SVC, absent }\end{array}$ & B-PA (alive) & $\begin{array}{l}\text { Pul, valvotomy } \\
\text { IVC }\end{array}$ & $\begin{array}{l}\text { Misdiagnosis } \\
\text { [Polysplenia] }\end{array}$ \\
$\begin{array}{l}\text { PS, A-V canal, bilat. } \\
\text { SVC }\end{array}$ & B-PA (alive) & & \begin{tabular}{c} 
Improved \\
\hline
\end{tabular}
\end{tabular}

into the left-sided venous atrium and the dilated azygos vein into the superior vena cava. The inferior vena cava was absent and the hepatic vein drained directly into the venous atrium. After inserting venous cannulae, one into the superior vena cava and the other into the hepatic vein, complete extracorporeal circulation was instituted and the atrium was opened. The atrial septal defect was secundum type and $5 \mathrm{~mm}$ in diameter. Two pulmonary venous openings were in the venous atrium. The atrial septal defect was enlarged by a longitudinal $2 \mathrm{~cm}$ incision and the right rim was displaced so as to cover the openings of the left pulmonary veins, and sutured, thus leading blood from the anomalous left pulmonary veins into the right-sided arterial atrium. In order to enlarge the extremely diminished atrial chamber caused by septal plasty, a diamond-shaped pericardial patch was inset in the venous atrial wall. The patient is doing well 5 years postoperatively.

\section{Levocardia}

This malposition was encountered in 5 patients, ranging in age from 6 months to 20 years. All but one proved to be II. D-loop. Heterotaxy, with severe cyanosis. Major anomalies were single ventricle with $\mathrm{D}$-transposition and $\mathrm{A}-\mathrm{V}$ canal in most cases, frequently accompanied by bilateral superior venae cavae, absence of inferior vena cava, anomalous pulmonary venous return and/or pulmonary atresia. Total corrective surgery in such cases is usually considered impossible at present, yet there are some cases in which anatomical situation favors complete repair as shown in our Case L-1. Shunt operations were performed with the B-PA shunts in 3 cases and with the A-PA in 1 . Postoperative improvement was marked, cyanosis mostly disappearing, except Case L-2 who died from misjudgement of the anatomy during the operation. Apparently the best approach was through a left third intercostal space incision for the B-PA shunt operation, and through a right third or fourth intercostal route for A-PA shunt. In the latter, a transsternal approach was deemed more favorable. In any case, special attention must be made to limit the caliber of an anastomosis within $4 \mathrm{~mm}$. Asplenia was in 3 , while polysplenia in 2 cases.

Case L-1: A 2-month-old girl was diagnosed as I. D-loop. Heterotaxy, 
TABLE 4. Associated anomalies

\begin{tabular}{|c|c|c|c|c|c|}
\hline Associated anomalies & $\begin{array}{c}\text { D-8 } \\
10 \text { days }\end{array}$ & $\begin{array}{c}\mathrm{D}-9 \\
1 \mathrm{mo} .\end{array}$ & $\begin{array}{c}\mathrm{L}-1^{*} \\
2 \text { mo. }\end{array}$ & $\begin{array}{l}\text { D-10 } \\
5 \text { mo. }\end{array}$ & $\begin{array}{c}\mathrm{L}-2 \\
6 \mathrm{mo} .\end{array}$ \\
\hline Single ventricle & + & + & & & + \\
\hline Ventricular septal defect & & & + & + & \\
\hline Single atrium & + & + & & & \\
\hline Atrial septal defect & & & & & + \\
\hline Common atrioventricular canal & + & + & & & + \\
\hline Pulmonary atresia or stenosis & + & + & & + & + \\
\hline Patent ductus arteriosus & + & + & + & + & + \\
\hline Partial anomalous pulmonary venous return & & & + & & \\
\hline Total anomalous pulmonary venous return & & + & & & + \\
\hline Transposition of the great arteries & & & & + & + \\
\hline Double outlet right ventricle & & & & & \\
\hline Bilateral superior vena cava & + & & & + & + \\
\hline Absence of inferior vena cava & + & + & + & & \\
\hline
\end{tabular}

associated with VSD, PDA, partial anomalous pulmonary venous return and absence of inferior vena cava.

Respiratory distress and heart failure occurred soon after birth and she was admitted to the Pediatric Service in our hospital and treated with digitalis. Heart failure persisted and she was clinically diagnosed incorrectly as having complete A-V canal with high pulmonary blood flow. On January 8, 1972, she was referred to us for emergency operation. Accordingly she was subjected to PAbanding by an extrapleural approach through a left thoracotomy. Six hours after surgery she died with ventricular fibrillation. The postmortem examination confirmed that the major anomaly was a VSD $7 \mathrm{~mm}$ in diameter, accompanied by the aforementioned diagnosis, and indicated that the anomalies has been potentially correctable. Visceral anomalies included the presence of 2 spleens, a right-sided stomach, a large transverse liver, gall bladder in the midline and 2 lobes in each lung, indicating polysplenia syndrome.

\section{Discussion}

Of the cardiac anomalies in malposition of the heart, those in mirror imagedextrocardia (IV.L-loop.Inversus) are the most simple in form and amenable to total correction, as are most cases in mesocardia. In determining the feasibility of total correction in these cases it is essential to ascertain the existence of pulmonary stenosis. In cases without pulmonary stenosis, the pulmonary-systemic resistance ratio will be the key to total correction. In the cases with pulmonary stenosis, the morphology of the stenosis as well as the peripheral vascular tree distal to the pulmonary bifurcation will determine the possibility and the relative difficulty of total correction. In general, such stenosis is located either at the pulmonary valve, its ring, or subvalvular conus. Technically most problematic 
in 15 patients of heterotaxy

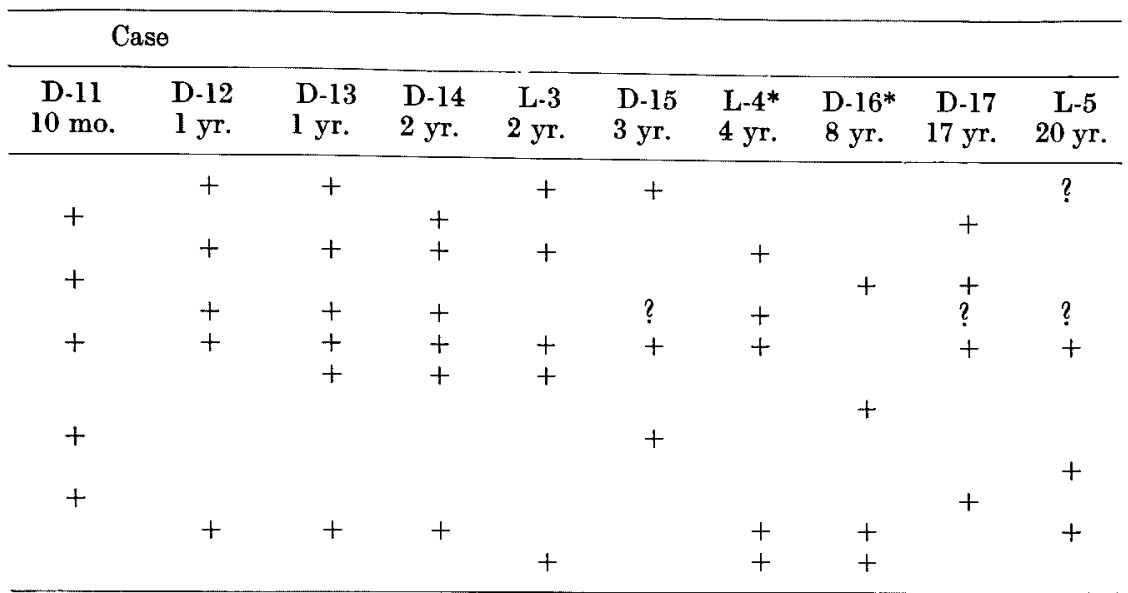

is the stenosis of the valve ring itself. In cases of IV.L-loop. Inversus which is a mirror image of normal, relief of the severe pulmonary stenosis for which ordinary procedure is inadequate can be done with an outflow patch plasty employed in tetralogy of Fallot. However, in cases of III.L-loop. Solitus (corrected transposition of the great arteries), relief of the valve annulus stenosis is extremely difficult. In these cases, the venous ventricular outflow tract is located posteriorly, with the right coronary artery lying over the anterior base of the pulmonary trunk, making any outflow patch plasty impossible. There is no subvalvular muscular tissue that has to be excised for relief of the stenosis because of the presence of the fibrous continuity between pulmonary and mitral valves (Horiuchi et al. 1968). Kiser et al. (1968) described a method of longitudinal incision and transverse approximation of the right-posterior portion of the stenotic valve annulus. This method, however, may not always be applicable. The most favorable alternative at present may be reconstruction of the pulmonary trunk with an aortic homograft as advocated by Rastelli et al. (1969) or with our pericardial valved tube-graft as in Case M-8. Intracardiac repair of corrected transposition of the great arteries can be done through a low and oblique $4 \mathrm{~cm}$ right ventriculotomy directed toward the apex, between the attachments of the anterior and posterior papillary muscles of the mitral valve. Though many controversial opinions exist regarding the side of the ventriculotomy, right-side ventriculotomy is deemed preferable since reconstruction of the pulmonary trunk may frequently be necessary. In open-heart surgery in these cases, it is important to keep in mind the presence of bilateral superior venae cavae and absence of inferior vena cava (Yamaguchi et al. 1970) which often resulted in technical modification of extracorporeal circulation.

Both dextrocardia and levocardia with heterotaxy exhibited complex associat- 
ed anomalies, most of which were not correctable at present. Therefore, in treating these cardiac malpositions, it is essential to check for asplenia or polysplenia. Three cases each presented by Leachman and Slovis (1964), Billig et al. (1968) and Iwabuchi and Niitsu (1971), and our 2 cases with polysplenia have been proved to be sccessfully corrected but all may represent rather exceptional instances. It would be worth reviewing the specific features of anomalies in such cases in connection with the possibility of functional correction. Complicated anomalies in cardiac malposition can be summarized as shown in Table 4. As also demonstrated by Sakakibara and Nakajima (1968) in 13 autopsied cases, heterotaxydextrocardia and levocardia cases are featured by "pulmonary atresia or stenosis, interatrial or interventricular communication as in single atrium or single ventricle, common atrioventricular canal and malposition of the great arteries." Of these most unbendingly resisting factors against total correction are 1) pulmonary atresia, 2) single ventricle and 3) common atrioventricular canal. Pulmonary atresia in the first place is regarded as generally reparable with reconstruction of the pulmonary trunk mentioned above. Single ventricle in the second place is also expected to become correctable with septal plasty in the near future (Horiuchi et al. 1970; Arai et al. 1972; Ionescu et al. 1973; Edie et al. 1973). Relatively dismal in prospect is the repair of the third anomaly, common atrioventricular canal. Total correction of all intracardiac anomalies attempted by Taguchi et al. (1968) by means of double valve replacement and extension graft of the ventricular septum can not be applied to all the cases. Nonetheless, it is believed that total correction of cardiac anomaly of this category would become feasible some day in future when an ideal artificial valve appears.

\section{References}

1) Arai, T., Hiyama, T., Miura, I., Takayasu, S., Morikawa, T., Akabane, I., Takao, A. \& Ando, M. (1972) Total correction of A type single ventricle-two successful cases. Jap. J. Thorac. Surg. (Jap.), 25, 394-400.

2) Billig, D.M., Hallman, G.L., Bloodwell, R.D. \& Cooley, D.A. (1968) Surgical treatment of cardiac defects associated with variations in cardiac position. J. Thorac. Cardiovasc. Surg., 55, 80-87.

3) Edie, R.N., Ellis, K., Gersony, W.M., Krongrad, E., Bowman, F.O. \& Malm, J.R. (1973) Surgical repair of single ventricle. J. Thorac. Cardiovasc. Surg., 66, 350360 .

4) Horiuchi, T., Abe, T., Okada, Y., Kuribayashi, R., Suzuki, Y. \& Ishizawa, E. (1971) Reconstruction of the main pulmonary artery with valve-bearing tube graft made of autologous pericardium. J. Thorac. Cardiovasc. Surg., 62, 793-802.

5) Horiuchi, T., Abe, T., Okada, Y., Suzuki, Y., Ishitoya, T., Onogi, H., Sato, T., Kano, K. \& Takamiya, M. (1970) Feasibility of total correction for single ventricle: A report of total correction in a six-year-old girl. Jap. J. Thorac. Surg. (Jap.), 23, 434 441.

6) Horiuchi, T., Koyamada, K., Abe, T., Taira, Y.\& Sato, S. (1968) A report of successful correction of corrected transposition of the great vessels with tetralogy of Fallot, with special reference on its surgical treatment. Jap. J. Thorac. Surg. (Jap.), 21, 409415.

7) Ionescu, M.I., Macartrey, F.J. \& Wooler, G.H. (1973) Intracardiac repair of single 
ventricle with pulmonary stenosis. J. Thorac. Cardiovasc. Surg., 65, 602-607.

8) Iwabuchi, K. \& Niitsu, K. (1971) Levocardia with anomalous venous drainage: A case with successful surgical correction. Jap. Heart. J. (Jap.), 12, 96-104.

9) Kiser, J.C., Ongley, P.A., Kirklin, J.W., Clarkson, P.M. \& McGoon, D.C. (1968) Surgical treatment of dextrocardia with inversion of ventricles and double outlet right ventricle. J. Thorac. Cardiovasc. Surg., 55, 6-15.

10) Leachman, R.D. \& Slovis, A.J. (1964) Relationship of the azygos venous system to normal atrial situs in levocardia. Circulation, 29, 901-904.

11) Paul, M.H., Muster, A.J., Sinha, S.A., Cole, R.B. \& Van Praagh, R. (1970) Doubleoutlet left ventricle with an intact ventricular septum; clinical and autopsy diagnosis and developmental implications. Circulation, 41, 129-140.

12) Rastelli, G.C., McGoon, D.C. \& Wallace, R.B. (1969) Anatomic correction of transposition of the great arteries with ventricular septal defect and subpulmonary stenosis. J. Thorac. Cardiovasc. Surg., 58, 545-552.

13) Sakakibara, S. \& Nakajima, K. (1968) Cardiac anomaly and asplenia syndrome. Nihon Rinsho (Jap.), 26, 2580-2581.

14) Taguchi, K., Sasaki, N., Okii, Y., Matsuura, Y. \& Hirao, M. (1968) Surgical experience with persistent common atrioventricular canal in a series of eighty-two patients: particular consideration on the correction of valve incompetence and deficiency of ventricular septum. J. Thorac. Cardiovasc. Surg., 55, 501-517.

15) Van Praagh, R. (1968) Malposition of the heart. In: Heart Disease in Infants, Children and Adolescents, edited by A.J. Moss \& F.H. Adams, Williams \& Wilkins, Baltimore, p. 602.

16) Yamaguchi, K., Takamiya, M., Watanabe, N., Takahashi, H., Odawa, K., Horiuchi, T., Koyamada, K., Ishitoya, T., Abe, T., Okada, Y., Onogi, H., Sato, T. \& Kano, K. (1970) Absence of the inferior vena cava, Report of 7 cases. Clin. Radiol. (Jap.), 15, 94-105. 